ISSN: 2542-0259

(c) Российское конкурентное право и экономика, 2019

\section{Даниловская А. В.,} ФГБОУ ВО «Хабаровский государственный университет экономики и права»,

г. Хабаровск

\section{Межотраслевой подход к исследованию понятия «Конкуренция»}

\begin{abstract}
Аннотация
Конкуренция как один из системообразующих факторов существования и развития рыночной экономики вызывает интерес у представителей разных научных областей. В статье приводится сравнительный анализ экономического, социологического, психологического и философского понимания сущности конкуренции и связанных с ней явлений. Приведены различные классификации видов конкуренции. Предлагается авторское понимание конкуренции, основанное на критериях и результатах межотраслевого исследования конкуренции, сделанные на их основе выводы дают более глубокие знания о конкуренции и ее значении для экономики страны и общества.
\end{abstract}

Ключевые слова: конкуренция, конкуренция-сотрудничество, межотраслевая сущность конкуренции.

\title{
Intersectoral approach to the study of the concept of "competition"
}

\section{Anna V. Danilovskaia,} Khabarovsk State University of Economics and Law, Khabarovsk

\section{Annotation}

Competition, as one of the system-forming factors for the development and existence of a market economy, is of interest among representatives of various scientific fields. The article provides a comparative analysis of the economic, sociological, psychological and philosophical understanding of the nature of competition and its related phenomena. The results of the inter-sectoral competition research and the conclusions based on them provide deeper knowledge of competition and its significance for the country's economy and society.

Keywords: competition, competition-cooperation, the interdisciplinary nature of competition. 
$\mathrm{K}$ онкуренция - сложное, многоаспектное явление, научные представления о которой не являются однозначными. В доктрине понятие конкуренции изучается как в экономическом значении, так и в философском, социальном, психологическом и юридическом. Межотраслевое понимание конкуренции дает возможность не только оценить ее с позиции официальной терминологии, приведенной в Федеральном законе от 26 июля 2006 г. № 135-Ф3 «0 защите конкуренции» (далее - 3акон о защите конкуренции) ${ }^{1}$, но и выйти за его рамки, что обеспечивает более полное представление о ее природе.

Изначально конкуренцию следует рассматривать как экономическое явление, связанное с развитием рыночных отношений. В научной литературе выделяется множество оснований для классификации подходов к определению сущности конкуренции, объединивших в себе все ранее известные и современные концепции конкуренции [1-3]. Наиболее обсуждаемыми среди экономистов являются поведенческий, структурный и функциональный [4, 5] подходы. Помимо этого, применяется профессионально ориентированный подход как одно из направлений поведенческого подхода. Данное учение рассматривает конкурентные действия участников рынка, совершаемые ими в ходе исполнения профессиональных функций в сферах производства и реализации товаров (работ, услуг), где конкуренция понимается как функция участия в конкуренции, обязательная для всех участников рынка. Потребительский подход, нацеленный на исследование значения конкуренции для потребителей, определяет конкуренцию полезной и эффективной в процессе отстаивания и укрепления потребительских интересов, реализации потребительских ожиданий и достижения потребительского благосостояния [4, 5].

Конкуренция в основном понимается как борьба, соперничество, что нашло отражение в официальной терминологии, содержащейся в ст. 4 Закона о защите конкуренции. Однако это далеко не всегда так. Конкуренция в целом и ее отдельные виды в частности проявляются в конкурентных действиях хозяйствующих субъектов, осуществляемых в отношениях друг с другом, в связи с чем говорят о стратегии конкурентных действий, имеющих определенные виды и цели. Среди видов конкурентных действий, не имеющих признаков соперничества, выделяют интеграцию (может быть как добровольной, так и принудительной), кооперацию с конкурентами, выражающуюся в создании стратегических альянсов, стратегию компромисса с конкурентами [6].

Тенденции сближения общих целей и интересов хозяйствующих субъектов-конкурентов повлияли на формирование в теории конкуренции концепции «конкуренция - сотрудничество» или «соконкуренция». Возникнув

См.: Официальный интернет-портал правовой информации (www.pravo.gov.ru) в результате трансформации рыночных условий, изза которой отмечается интенсивный рост межфирменной кооперации в различных формах [7], данная концепция исходит из преимуществ сотрудничества над конкуренцией, их взаимовыгодного сочетания [1]. Причины появления такой формы взаимодействия хозяйствующих субъектов, на наш взгляд, состоят, во-первых, в укрупнении субъектов и сокращении их количества в результате монополизации, развитии транснациональных корпораций, интеграции, а во-вторых, в международной кооперации капитала, долговременных договорных связях, планомерности [8].

Между тем объединения хозяйствующих субъектов являются предметом внимания антимонопольных и правоохранительных органов, стремящихся не допустить антиконкурентные соглашения или пресечь уже заключенные. Наиболее опасными среди таких соглашений признаны картели - создание и участие в них влечет уголовную ответственность по ст. 178 УК РФ. В то же время в научной литературе, с одной стороны, отмечается недооцененное в сравнении с конкуренцией значение кооперации в экономическом процессе [9], а с другой в связи с прогрессированием этих тенденций и их положительной оценкой - обострение в современной российской экономике проблем защиты конкуренции [10].

Конкуренция обладает общественной значимостью, которая определяется на основе идеологического и экономического подходов. Сторонники первого указывают на то, что конкуренция позволяет достичь социально справедливого распределения результатов функционирования экономики. Через второй подход обосновываются преимущества конкуренции перед иными способами распределения ограниченных ресурсов в целях удовлетворения потребностей [11]. Сформированный на основе идеологического и экономического подходов синтетический подход в своей основе имеет тезис о неспособности конкуренции самостоятельно эффективно распределять наличные ресурсы общества, вследствие чего требуется корректировка со стороны государства, формой которой называется защита конкуренции государством [11].

Вышеизложенные экономические толкования понятия конкуренции содержат описание ее сущности в общем, в то время как в экономической теории принято деление конкуренции на многочисленные виды - свободная, ограниченная, совершенная, несовершенная, монополистическая, цивилизованная, нецивилизованная, эффективная, разумная, ценовая, неценовая, регулируемая, внутриотраслевая, межотраслевая, национальная, иностранная, авторегулирующая, формирующая, развивающая, координирующая, активная, пассивная, слабая, недобросовестная и другие [2], каждая из которых обладает своими признаками и особенностями.

При этом современная экономическая теория основывается на модели совершенной конкуренции, которая, хотя и далека от истинного состояния конкуренции 
на современных рынках, остается более предпочтительной, чем иные [12]. Экономисты указывают на то, что, на самом деле, конкуренция постоянно подвергается изменениям, переходя из одного качества в другое, не носит совершенный или несовершенный характер [2]. Отсюда очевидно, что не может быть точного ответа на вопрос, поднимаемый в юридическом научном сообществе: какую конкуренцию поддерживает Конституция РФ? [13].

Нередким объектом исследования конкуренция является в социологии, в которой институт конкуренции рассматривается во взаимосвязи с социальными институтами, системой социальных отношений. Экономическая социология представляет конкуренцию как социальное действие, ориентированное на других участников рынка, при которой между прямыми конкурентами, не вступающими друг с другом в экономические сделки, возникает сложный комплекс социальных связей, обеспечивающих общую устойчивость рынка [14]. Согласно суждению классика социологии М. Вебера, конкуренция - это мирная борьба, состоящая в использовании формально мирных средств для получения права распоряжаться возможностями, обладать которыми стремятся и другие [15], конкуренция называется регулируемой, если при выборе целей и средств ориентируется на определенный порядок [15].

В развитие приведенного социологического классического понимания конкуренции используется экономикосоциологический подход, в основе которого лежит тезис отрицания независимости хозяйствующих субъектов. Согласно этому учению конкуренция представляется как: 1) социально укорененный процесс (основана на социальных контактах, исключающих независимость хозяйствующих субъектов; сама конкуренция рассматривается как постоянное соотнесение деловых стратегий, а не как столкновение, чреватое конфликтами); 2) установление социального порядка (ведущие на рынке хозяйствующие субъекты создают условия институционального оформления конкуренции, устанавливают согласованный конкурентный порядок, определяя правила. В связи с чем конкуренция на рынке поддерживается не только правовыми нормами, но и специально встроенными ограничениями, разработанными самими участниками рынка, которые восполняют имеющийся по различным причинам пробел в правовом регулировании); 3) символическая борьба (в силу наличия на рынках самых разнообразных товаров большое значение для эффективности деятельности конкурентов имеет то, как они представляют этот товар на рынке, чему способствует использование средств индивидуализации) [16].

Социологами предлагаются иные классификации видов конкуренции. Так, В.В. Радаев предлагает разделять конкуренцию в сфере хозяйства и собственно экономическую конкуренцию, т. К. в хозяйственной сфере осуществляются как экономические, так и неэкономи- ческие действия, в основе которых лежат методы, не основанные на превосходстве в эффективности и преследующие цели неэкономического характера [17]. В связи с чем выделяет экономически обусловленную и неэкономически ориентированную конкуренцию, которая, в свою очередь, может быть соревновательной и хищнической [16]. Не обусловленная экономически «хищническая» конкуренция представляет собой с позиции уголовного права общекриминальный тип поведения, т. к. нацелен на ухудшение положения конкурентов, вплоть до применения средств физического насилия или уничтожения их собственности.

Затрагивая самые разные стороны человеческой жизни, конкуренция стала предметом исследования и в психологии. В редких научных работах, посвященных анализу конкуренции, она рассматривается как одна из основных форм организации межличностного взаимодействия, характеризующегося достижением индивидуальных или групповых целей, интересов в условиях противоборства с добивающимися этих же целей и интересов других индивидов или групп [18]. Одновременно конкуренция это то, что постоянно подстерегает участников всякого сотрудничества, если одна из сторон (или обе) вдруг нарушает базовые договоренности [19].

Психологические исследования конкуренции указывают на то, что субъекты экономической деятельности, конкурируя друг с другом и допуская жесткие методы борьбы, в то же время заинтересованы в продуктивной партнерской конкуренции, основанной на знаниях и инновациях. При этом, не рассчитывая на эффективность закона, государство не рассматривается ими как гарант поддержания честных правил [18]. Отмечается, что в развитии конкуренции значимую роль играют стратегические альянсы, которые укрепляют сотрудничество индивидуальных фирм и выводят конкуренцию на новый уровень - между группами фирм с разными интересами [18].

Изложенные выше выводы социологических и психологических исследований явления конкуренции, объясняющие причины процессов объединения хозяйствующих субъектов как развитие конкурентных отношений подтверждают давно существующую экономическую концепцию тесной и неизбежной связи конкуренции и монополий. С этой позиции вполне логичными представляются сложившиеся в экономике страны тенденции картелизации, борьбе с которой, включая уголовноправовые средства, государство придает особо важное значение.

Таким образом, помимо того что объединение хозяйствующих субъектов - это, по сути, естественное явление, можно также заключить, что отсутствие достаточного и эффективного правового регулирования в сфере конкуренции добавляет ускорения этим процессам.

Примечательно, что «взаимодействие» является ключевым моментом и в конкуренции [20], и при объеди- 
нении хозяйствующих субъектов на основе различного рода соглашений, включая противоправные (антиконкурентные соглашения). Взаимодействуя посредством конкуренции или на основе соглашений, хозяйствующие субъекты реализуют свои интересы, стремясь их удовлетворить наилучшим для себя способом, исходя из складывающейся на рынке ситуации. Таким образом, такое поведение научно объяснимо необходимостью приспосабливаться к меняющимся экономическим условиям в целях сохранения своих интересов.

Помимо социологического и психологического представлений о конкуренции интерес представляют и философские взгляды на нее, некоторые из которых содержат идею о прямом соотношении конкуренции и сотрудничества, взаимодействия. Так, А. В. Щербина, представляя конкуренцию как состязательное взаимодействие хозяйствующих субъектов, сопровождающееся процветанием одних и упадком или разорением других [21], в то же время полагает необходимым понимать конкуренцию не как «войну всех против всех», а как форму сотрудничества, что, по его мнению, является более содержательным и отвечающим реалиям современной экономической культуры [21].

В философской науке сложились два подхода к пониманию конкуренции. Согласно неономинализму конкуренция - стихийно складывающийся атрибут рыночного типа экономики. В неореализме конкуренция рассматривается как предмет сознательного насаждения или выведения на периферию экономической жизни экономики планового типа (неореализм) [22]. Неономинализм не приемлет какого-либо вмешательства государства, усматривая в этом посягательство на экономическую свободу, что рассматривается как некий произвол, в то время как в неореалистической концепции конкуренция появляется и развивается благодаря необходимой деятельности государства, которая осуществляется посредством законодательного закрепления новых институтов конкуренции, принятия планов и «дорожных карт» развития конкуренции [22].

Помимо этого, в философии конкуренция нередко рассматривается как механизм, который дает возможность количественно и качественно определить степень вероятности того или иного результата, разрешения противоречий при многовариантном развитии событий; она - не только деятельность, но и характеристика состояния личности, группы, общества [23]. В контексте изучения связи между понятиями «конкуренция» и «стабильность» нельзя не отметить, что механизм конкуренции дает возможность выделить факторы и условия, которые способствуют формированию вариантов будущей стабильности [23].

Вопросы конкуренции, конкурентных ситуаций и, в частности, соблюдения моральных требований во взаимоотношениях между конкурентами являются одной из проблем, которые относительно недавно стали подниматься в философии морали. В частности, Д. МакКаллумом были обозначены этические стороны конкуренции, такие как моральное право одного лица потребовать прекращения деятельности другого, возможность получить блага более легкими путями, чем участвуя в конкуренции за них, или состояние незащищенности, которое порождает конкуренция. Анализируя нормативное разграничение между честной и нечестной конкуренцией, философ приходит к выводу о том, что это различие и приоритет честной конкуренции необходимы ради целей защиты тех, кто не участвует в конкуренции, от нанесения ущерба в процессе конкурентной борьбы и защиты самих конкурентов и неконкурентов от поведения, выходящего за рамки морали и приличий. Однако, как отмечено им, истина конкурентных отношений лежит гораздо глубже поверхностного понимания мотивов и целей конкурентов, «которые могут быть считаны с их конкурентного статуса» [24].

Таким образом, анализ понятия конкуренции как экономического, социального, психологического и философского явления приводит к выводу о межотраслевой сложной природе конкуренции как необходимого, желательного и нежелательного для хозяйствующих субъектов элемента рыночной экономики, основанного на их противостоянии и взаимодействии (объединении), поддерживаемого правовыми и иными правилами, которые они учитывают (реализуют) в своей деятельности, руководствуясь не только целями получения прибыли, но и социальными мотивами, обеспечивающими стабильность экономического процесса и социального порядка. Межотраслевой подход в изучении понятия конкуренции демонстрирует многосторонность ее значимости для общества, позволяет получить ответы на многие вопросы о ценности конкуренции, объяснить и прогнозировать экономические процессы, происходящие в триаде «конкуренция - монополия - государство», усовершенствовать законодательное закрепление соответствующих правовых норм.

Следствием последнего должно стать формирование такой государственной конкурентной политики, которая будет соответствовать как публичным, так и частным интересам.

\section{Литература}

1. Архипова Л. С., Гагарина Г. Ю., Архипов А. В. Конкуренция как основа экономики: концептуальные подходы к исследованию роли конкуренции: Монография. М.: ИНФРА-М, 2015. С. 9-81.

2. Кравцевич С. В. Историко-экономические взгляды на формирование представлений о конкуренции: Монография. Чита: ЧитГУ, 2011. С. 106-139.

3. Платонова Е.Д. Об общенаучных подходах к исследованию конкуренции и конкурентных отно- 
шений // Современная конкуренция. 2007. № 4 (4). С. 104-113.

4. Жигун Л.А., Третьяк Н. А. Методологические основы динамических состояний конкуренции // Современная конкуренция. 2008. № 4. С. 18-29.

5. Бисикало Е.Э. Основные подходы к оценке конкуренции в переходной экономике // Известия Иркутской государственной экономической академии. 2011. № 4. [Электронный ресурс]. Доступ с сайта Научной электронной библиотеки Elibrary.ru // URL: https://elibrary.ru/download/ elibrary_16498102_15071236.pdf (Дата обращения: 10.02.2019).

6. Рубин Ю.Б. Стратегии конкурентных действий // Современная конкуренция. 2014. № 4 (46). С. 101-141.

7. Хмелькова Н.В. От конкуренции к соконкуренции: новая логика конкурентного сотрудничества // Журнал экономической теории. 2010. № 1. C. $145-155$.

8. Гордеев В.А. Конкуренция и ее динамика в зеркале теоретической экономии // Теоретическая экономика. 2013. №6. С. 17-25.

9. Кирдина-Чэндлер С.Г., Холл Д. Кооперация versus конкуренция в трудах российских эволюционистов // Journal of institutional studies (Журнал институциональных исследований). Т. 9. 2017. № 1. С. 6-26.

10. Мальцева О.В. Анализ проблем и оценка уровня развития конкуренции в России // Вопросы регулирования экономики. 2014. Т. 5. № 1. С. 69-76.

11. Конкурентное право России: Учебник / Д. А. Алешин, И. Ю. Артемьев, И. В. Башлаков-Николаев и др. Отв. ред. И. Ю. Артемьев, С. А. Пузыревский, А. Г. Сушкевич; Нац. исслед. ун-т «Высшая школа экономики». 2-е изд., перераб. и доп. М.: Изд. дом Высшей школы экономики, 2014. С. 21-24.

12. Светуньков С.Г. Теория конкуренции: абстрактное и идеализированное // Современная конкуренция. 2009. № 4 (16). С. 60-66.

13. Конкуренция в рыночной экономике: пределы свободы и ограничений (обзор XI Ежегодных научных чтений памяти профессора С.Н. Братуся) // Журнал российского права. 2017. № 1. С. 38-51.

14. Радаев В.В. Атомизированные действия и социальные связи: основы конкуренции в российской розничной торговле // Мир России. 2009. №2. С. 50-88.

15. Вебер М. Хозяйство и общество: очерки понимающей социологии: в 4 т. / Макс Вебер; [пер. с нем.]. Нац. исслед. ун-т «Высшая школа экономики». М.: Изд. дом Высшей школы экономики, 2016. Т. 1. Социология. С. 96-368.
16. Радаев В.В.Социология рынков: к формированию нового направления. М.: ГК ВШЭ, 2003. С. 49-58.

17. Радаев В.В. Что такое экономическое действие? // Экономическая социология. 2002. Т. 3. № 5. С. 1825. [Электронный ресурс]. Электронный журнал «Экономическая социология» // URL: https://ecsoc. hse.ru/data/2011/12/08/1208205039/ecsoc_t3_ n5.pdf\#page=18 (Дата обращения: 20.03.2019).

18. Ахадова Н. А. Особенности отношения к конкуренции в сферах политики и предпринимательства в современной России: Автореф. дис. ... канд. психолог. наук. СПб., 2004. С. 5-23.

19. Шмелев А.Г. Конкуренция как метакатегория современной психологии. Сообщение 2 // Вестник ЮУрГУ. Серия Психология. Т. 7. 2014. № 4. С. 105-113.

20. Шмелев А.Г. Конкуренция как метакатегория современной психологии. Сообщение 1 // Вестник ЮУрГУ. Серия Психология. Т. 7. 2014. №3. С. 97-108.

21. Щербина А. В. Конкуренция как проявление агональности в экономической культуре: Дис. ... докт. философ. наук. Ростов-на-Дону, 2006. С. 7-13.

22. Летунова О.В. Конкуренция как тип агональной деятельности (социально-философский анализ): Автореф. дис. ... канд. философ. наук. Красноярск, 2006. С. 6-17.

23. Янгирова С. М. Конкуренция и социальная адаптация в трансформирующемся обществе (социальнофилософский анализ): Автореф. дис. ... канд. философ. наук. Уфа, 2006. С. 3-6.

24. МакКаллум Д. Конкуренция и моральная философия [Электронный ресурс] // URL: https://www.hse. ru/data/2010/12/16/1208289854/MacCallum-ed2-1. doc (Дата обращения: 20.03.2019).

25. Рубин Ю.Б. Дискуссионные вопросы современной теории конкуренции // Современная конкуренция. 2010. № 3 (21). С. 38-67.

\section{Сведения об авторе}

Даниловская Анна Владимировна: кандидат юридических наук, доцент кафедры гражданского права и гражданского процессуального права Федерального государственного бюджетного образовательного учреждения высшего образования «Хабаровский государственный университет экономики и права»

Контактная информация:

Адрес: 680042, г. Хабаровск, ул. Тихоокеанская, д. 134

Тел.: +7 (4212) 37-49-43

E-mail: d_a_v@list.ru 